\title{
Experimental Demonstration of an Aluminum Fuelled Propulsion System for CubeSat Applications
}

\author{
Ahmed O. David ${ }^{1}$ and Aaron K. Knoll. ${ }^{2}$ \\ Surrey Space Centre, University of Surrey, Guildford, Surrey, GU2 8EY, United Kingdom

\section{I.Introduction}

$\mathrm{T}$

He inherent mass, volume, and power constraints of CubeSats puts a stringent limitation on the resources that can be allocated to the propulsion system without overly detracting from the other subsystems on board [1]. Both Chemical Propulsion (CP) and Electric Propulsion (EP) have been proposed for CubeSat applications, with different key constraints in each case. The limited on-board power restricts the use of highly fuel-efficient EP systems, while the $\mathrm{CP}$ systems have scaling related issues and require a larger mass and volume of the $1 U$ CubeSat for equivalent levels of $\Delta V$ [2]. Nevertheless, future CubeSat missions involving constellation or formation flight will require that the satellites be equipped with a propulsion system that can operate within the stringent resource limitations of the satellite and deliver enough $\Delta V$ for their orbital maintenance [3]. There are ongoing research activities in this regard aimed at miniaturizing the space proven and conventional propulsion systems, which can be found in [1, 4-5]. However, scaling of conventional propulsion systems to the size and power limitations of $1 U$ CubeSats, while retaining their operational performances is difficult and complex, and therefore requires the investigation of alternative approaches [6]. This study considers a CP alternative that utilizes aluminium wool as fuel and a mixture of sodium hydroxide and water as an oxidiser [7]. The novelty over conventional propellant combinations is that the reaction takes place at moderate temperatures and at a slow reaction rate. Additionally, the reactants are low cost, easy to handle and can be stored over a long duration without decomposing.

The proposed configuration of the propulsion system shown in Fig. 1, is designed to take about one-third of the volume of a $1 U$ CubeSat. It contains a reaction chamber with a nozzle, a plenum volume, two oxidiser tanks with bladders, two cool gas generators and three Lee extended performance valves (IEP Series with FFKM seal option). Table 1 shows the mass budget of the propulsion system. The total system mass is 126 grams, which is about $10 \%$ of a $1 U$ CubeSat. The volume is $10 \times 10 \times 3.25 \mathrm{~cm}^{3}$ (see Error! Reference source not found.), which represents about $30 \%$ of the total volume of the $1 U$ CubeSat.

\footnotetext{
${ }^{1}$ Ph.D Research Student, Surrey Space Centre, University of Surrey, Student Member AIAA.

${ }^{2}$ Lecture in Plasma Propulsion, Surrey Space Centre, University of Surrey, Member AIAA.
} 


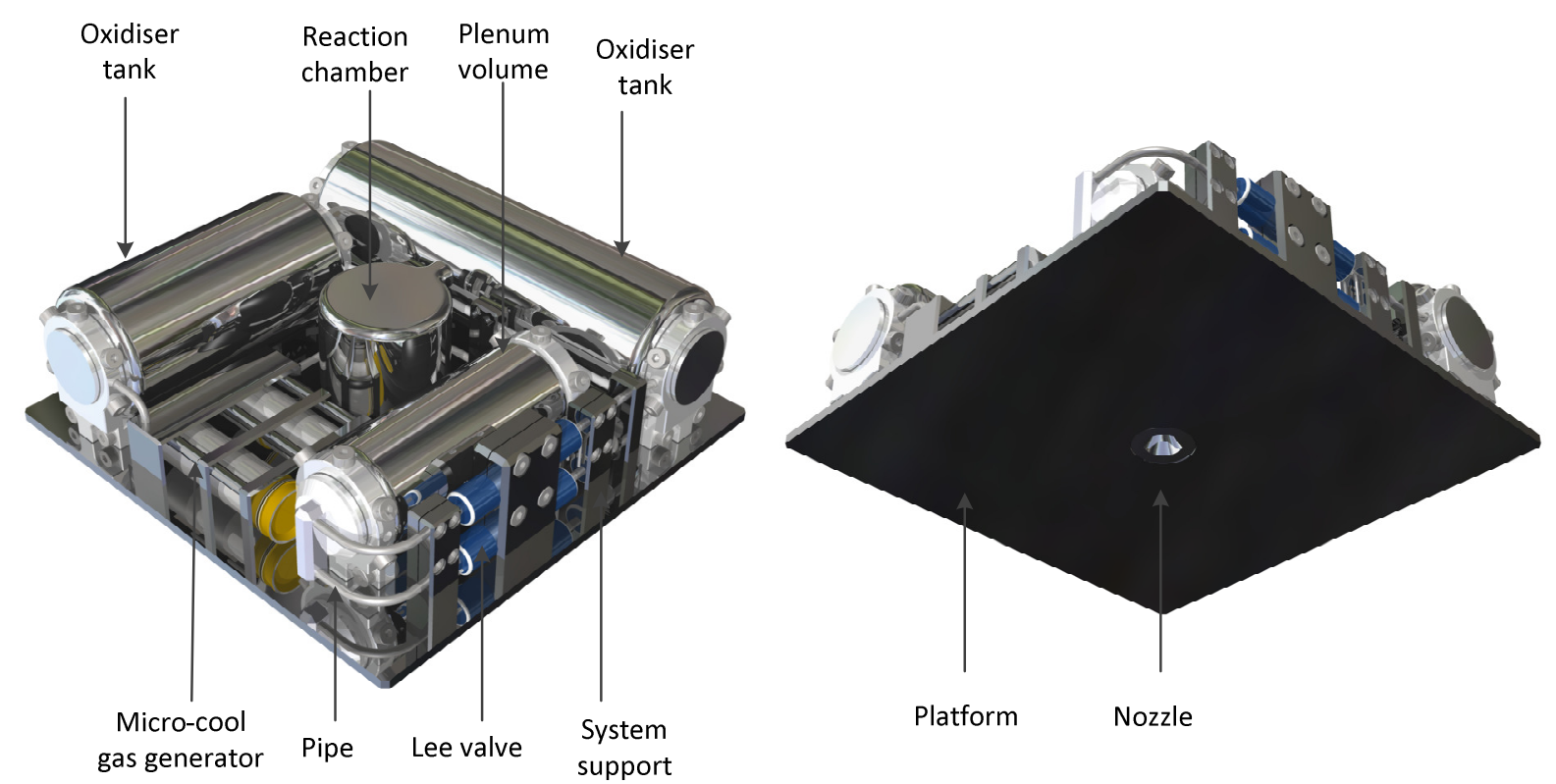

Fig. 1 Proposed assembly of hybrid propulsion system for CubeSat applications.

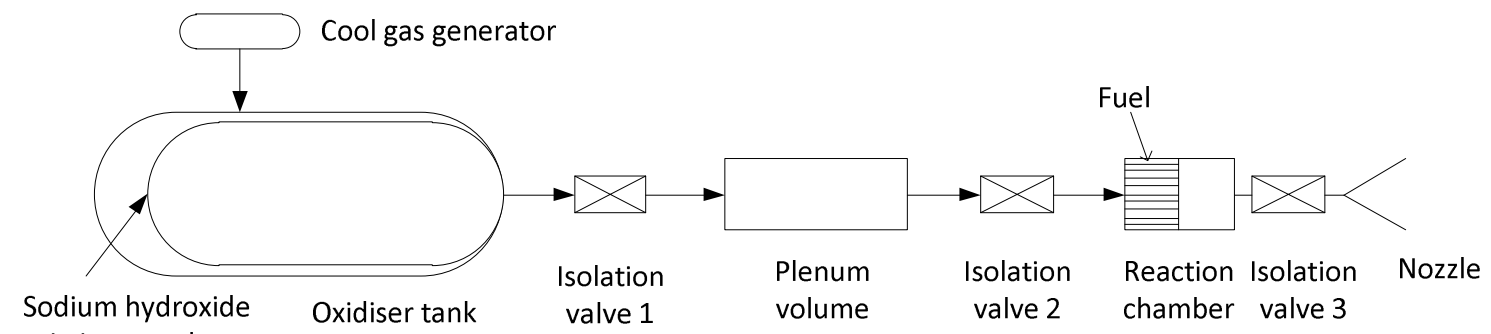
resistive membrane

Fig. 2 Schematic layout of the hybrid propulsion system

The aluminum wool is contained within the reaction chamber, and the oxidizer tanks hold the premixed $12.50 \mathrm{~mol} / \mathrm{kg}$ molar solution of sodium hydroxide and water. A micro-cool gas generator (from Cool Gas Generator Technologies) [8] is included for a blow down of the oxidiser from the oxidiser tank to the plenum volume once the first valve is opened (The generator has a total mass of $2 \mathrm{~g}$ and it produces of about $98 \%$ of nitrogen gas with a maximum pressure of 10 bar). The size of the plenum volume determines the amount of oxidizer that is introduced into the reaction chamber for each cycle of the valves. A third valve is placed between the reaction chamber and the nozzle to allow a build-up of pressure inside the reaction chamber once the propellants reaction starts, and also prevents passage of particles of aluminum wool and water droplets during the reaction. The valve is opened only when the operation of the thruster is needed. For oxidizer scaling purpose, the size of the plenum volume is set at about $6 \mathrm{ml}$ in this design.

Table 1 Mass prediction of the propulsion system 


\begin{tabular}{lccc}
\hline \multicolumn{1}{c}{ Components } & Mass (g) & No of Components & Total $(\mathrm{g})$ \\
\hline Oxidiser Tank. & 30 & 1 & 30 \\
Plenum Volume. & 8 & 1 & 8 \\
Reaction Chamber and & 10 & 1 & 10 \\
Nozzle. & & & \\
Pipe Work, Connectors & 62 & 1 & 62 \\
and Base Bracket. & 6 & 3 & 18 \\
Lee Valve. & 2 & 2 & 4 \\
Cool Gas Generator. & Total & & $\mathbf{1 3 2}$ \\
\hline \hline
\end{tabular}

\section{II.Energy Transfer of the Propulsion System}

A proof of concept experiment was constructed in order to evaluate the feasibility of the proposed propulsion system, in a representative vacuum environment. The experimental apparatus is depicted in Fig 3 , and is composed of a 316 stainless steel reaction chamber with a nozzle adopted from a Swagelok cap and plug. The nozzle had a throat diameter of $0.72 \mathrm{~mm}$, a flare angle of 14 degrees, and an expansion ratio of 40 . By applying energy conservation to the closed system depicted in Fig 4, and assuming that the heat losses through the side walls of the reaction chamber and nozzle are negligible (adiabatic approximation), we can arrive at the following expression equating the enthalpy of the reactants to the outgoing kinetic energy of the exhaust products:
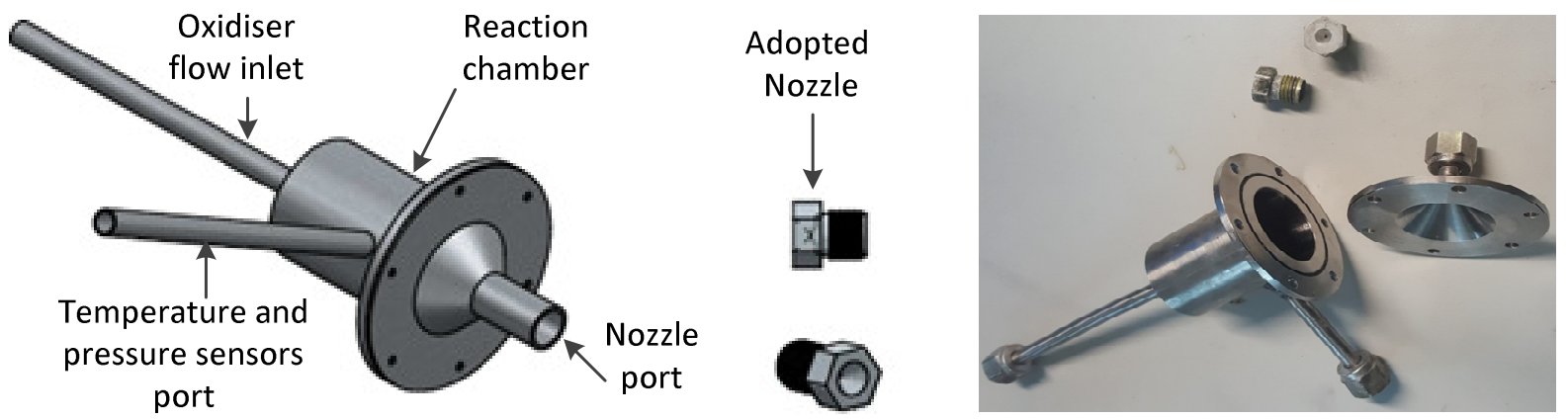

Fig. 3 Proof of concept design of reaction chamber of the propulsion system 


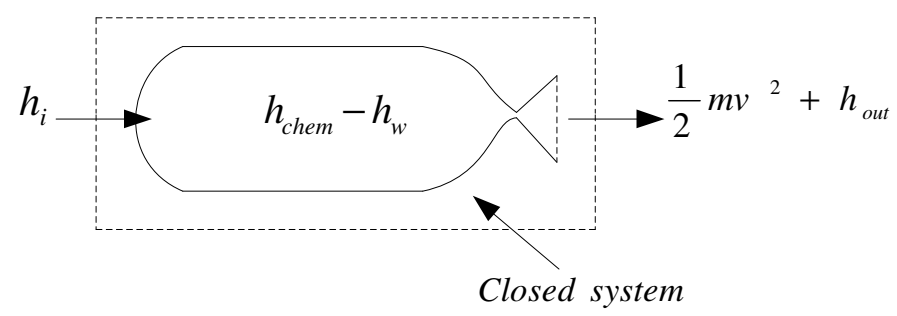

Fig. 4 Thruster treated as a closed control system

$$
h_{i}+h_{\text {chem }}=h_{w}+\frac{1}{2} m v^{2}+h_{\text {out }}
$$

where $h_{i}$ is the enthalpy of the liquid oxidizer injected into the system, $h_{c h e m}$ is the chemical enthalpy of reaction, $h_{w}$ is the enthalpy component responsible for water phase change, $\frac{1}{2} m v^{2}$ is the component of enthalpy for useful thrust, and $h_{\text {out }}$ is the enthalpy of the outgoing stream, which is assumed zero in this case for an ideal adiabatic system. It should be noted that the assumption of negligible heat loss through the side walls and nozzle may introduce errors to the analysis, especially in the case of a small thruster. Evaluation of the conductive heat losses through the mounting bracket, determined using 3 spatially separated thermocouples on the bracket, indicate a power loss of approximately $2 \mathrm{~W}$ during the experiment. With an assumption that the duration of the reaction and thrust production phase is approximately $50 \mathrm{~s}$, then we have a total heat loss on order $0.1 \mathrm{~kJ}$. Additionally, the variation in temperature of the reaction chamber and nozzles will account for additional losses of energy from the system owing to their heat capacity and thermal mass, which has not been accounted for within this preliminary analysis. We assumed the specific enthalpy of the injected oxidizer to be approximately equal to water at $23^{\circ} \mathrm{C}$, which is $96.518 \mathrm{~kJ} / \mathrm{kg}$ [9]. The specific enthalpy in the chamber, $h_{\text {chem }}$, is due to the formation of strong chemical bonds from the reactions:

$$
\begin{gathered}
2 \mathrm{Al}(s)+6 \mathrm{H}_{2} \mathrm{O}(l)+2 \mathrm{NaOH}(s) \rightarrow 2 \mathrm{NaAl}(\mathrm{OH})_{4}(a q)+3 \mathrm{H}_{2}(g)-\Delta H \\
\mathrm{NaAl}(\mathrm{OH})_{4}(a q) \rightarrow \mathrm{NaOH}(s)+\mathrm{Al}(\mathrm{OH})_{3}(a q) \\
\mathrm{Al}(\mathrm{s})+3 \mathrm{H}_{2} \mathrm{O}(\mathrm{l}) \rightarrow \mathrm{Al}(\mathrm{OH})_{3}(a q)+1.5 \mathrm{H}_{2}(g)-\Delta H
\end{gathered}
$$

While Equation 2 is the chemical reaction of the propellants, Equation 3 is a decomposition reaction of the sodium aluminate formed in the first reaction [10]. The resultant reaction is Equation 4. The liberated heat from the reaction has two components: standard enthalpy of formation and a temperature-dependent change of enthalpy of the reaction. The expression is given in [11] as 


$$
h_{c h e m}=\Delta h_{r x n}^{\circ}+\int_{T_{1}}^{T_{2}} c_{p}(T) d T
$$

The enthalpy of formation, $\Delta h_{r x n}^{\circ}$, is easily calculated using Hess's law [12], which states that the overall heat of reaction of a thermodynamic chemical reaction is equal to the sum of the heat of formation of the reaction products minus the sum of the heat of formation of the reactants. That is

$$
\Delta h_{r x n}^{\circ}=\sum \Delta h_{f(\text { products })}^{\circ}-\sum \Delta h_{f(\text { reactants })}^{\circ}
$$

where $\Delta h_{f(\text { reactants })}^{\circ}$ is the specific standard heat of formation of the reactants and $\Delta h_{f(\text { products })}^{\circ}$ is the specific standard heat of formation of the products. Table 2 shows the $\Delta h_{f}^{\circ}$ values used in the calculation, which are obtained from $C R C$ Handbook of Chemistry and Physics [13].

Table 2 Specific standard heat of formation of selected substances

\begin{tabular}{lccc}
\hline \hline Substances & Molar mass & $\begin{array}{c}\text { Enthalpy of } \\
\text { formation } \\
\mathrm{kJ} / \mathrm{mol}\end{array}$ & $\begin{array}{c}\text { Specific heat } \\
\left(\mathrm{c}_{\mathrm{p}}\right) \\
\mathrm{kJ} / \mathrm{mol} . \mathrm{K}\end{array}$ \\
\hline $\mathrm{Al}(\mathrm{s})$ & 0.0269815 & 0 & 0.0242 \\
$\mathrm{H}_{2}(\mathrm{~g})$ & 0.0020159 & 0 & 0.028868 \\
$\mathrm{H}_{2} \mathrm{O}(\mathrm{l})$ & 0.01801528 & -285.8 & - \\
$\mathrm{H}_{2} \mathrm{O}(\mathrm{g})$ & 0.01801528 & -241.8 & 0.036031 \\
$\mathrm{Al}(\mathrm{OH})_{3}(\mathrm{aq})$ & 0.0780036 & -1276 & -0.128706 \\
\hline \hline
\end{tabular}

The temperature limits, $T_{1}$ and $T_{2}$, of the second term in Equation 5 are the initial and the final temperature points in the reaction chamber. The temperature-dependent heat capacity, $c_{p}$, is given in $[11,14]$ as

$$
c_{p}(T)=a+b T+c T^{2}
$$

Therefore,

$$
\int_{T_{1}}^{T_{2}} c_{p}(T) d T=a T+\frac{b T^{2}}{2}+\left.\frac{c T^{3}}{3}\right|_{T_{1}} ^{T_{2}}
$$

where the constants $a, b$ and $c$ are obtained from [9] and shown in Table 3. These values are within the reaction chamber operating temperature.

Table 3 Heat capacity coefficients

\begin{tabular}{lrrr}
\hline \hline Substances & \multicolumn{3}{c}{ Heat capacity coefficients from $300 \mathrm{~K}$ to $1000 \mathrm{~K}$} \\
& $\mathrm{a}(\mathrm{J} / \mathrm{mol} . \mathrm{K})$ & $\mathrm{b}\left(10^{-2} \mathrm{~J} / \mathrm{mol}^{2} \mathrm{~K}^{2}\right)$ & $\mathrm{c}\left(10^{-5} \mathrm{~J} / \mathrm{mol}^{\mathrm{K}} \mathrm{K}^{3}\right)$ \\
\hline
\end{tabular}




\begin{tabular}{lccc}
\hline $\mathrm{Al}(\mathrm{s})^{3}$ & 28.08920 & -0.5414849 & 0.8560423 \\
$\mathrm{H}_{2}(\mathrm{~g})$ & 33.066178 & -1.1363417 & 1.1432816 \\
$\mathrm{H}_{2} \mathrm{O}(\mathrm{l})^{4}$ & -203.6060 & 152.3290 & -319.6413 \\
$\mathrm{H}_{2} \mathrm{O}(\mathrm{g})^{5}$ & - & - & - \\
$\mathrm{Al}(\mathrm{OH})_{3}(\mathrm{aq})$ & 2.987191 & 10.7087 & -8.95576 \\
\hline
\end{tabular}

The energy gained by the reaction exhaust is used to increase the kinetic energy into directed energy through the converging-diverging nozzle.

\section{III.Experimental Results}

Table 4 shows a summary of the experimental data that was used to determine the energy utilisation efficiency of the propulsion system. A thrust stand with an accuracy of approximately $\pm 0.1 \mathrm{mN}$ [15] was used to take the thrust measurements. The raw time traces of thrust, reaction chamber temperature, and reaction chamber pressure are shown in Fig. 5, Fig. 6 and Fig. 7.

Table 4 Experimental data for energy utilisation of the propulsion system

\begin{tabular}{|c|c|c|c|c|c|c|c|c|c|}
\hline $\begin{array}{l}\text { Mass of } \\
\text { Fuel } \\
\text { (g) }\end{array}$ & $\begin{array}{l}\text { Mass of } \\
\text { Oxidiser } \\
(\mathrm{g})\end{array}$ & $\begin{array}{l}\text { No of } \\
\text { injection }\end{array}$ & $\begin{array}{l}\text { Propellar } \\
\text { Remn'g } \\
\text { mass (g) }\end{array}$ & $\begin{array}{l}\text { mass } \\
\text { Exht'd } \\
\text { mass (g) }\end{array}$ & $\begin{array}{l}\text { Exhau } \\
\text { compc } \\
\mathrm{H}_{2}(\mathrm{~g})\end{array}$ & $\begin{array}{l}\text { Ist } \\
\text { osition }(\%) \\
\mathrm{H}_{2} \mathrm{O}(\mathrm{g})\end{array}$ & $\begin{array}{l}\text { Average } \\
\text { thrust (N) }\end{array}$ & $\begin{array}{l}\text { Specific } \\
\text { impulse } \\
\text { (s) }\end{array}$ & $\begin{array}{l}\text { Total } \\
\text { impulse } \\
(\mathrm{Ns})\end{array}$ \\
\hline 6 & 3 & 1 & 7.46 & 1.54 & 1.77 & 98.23 & 0.0047 & 45 & 0.6792 \\
\hline
\end{tabular}

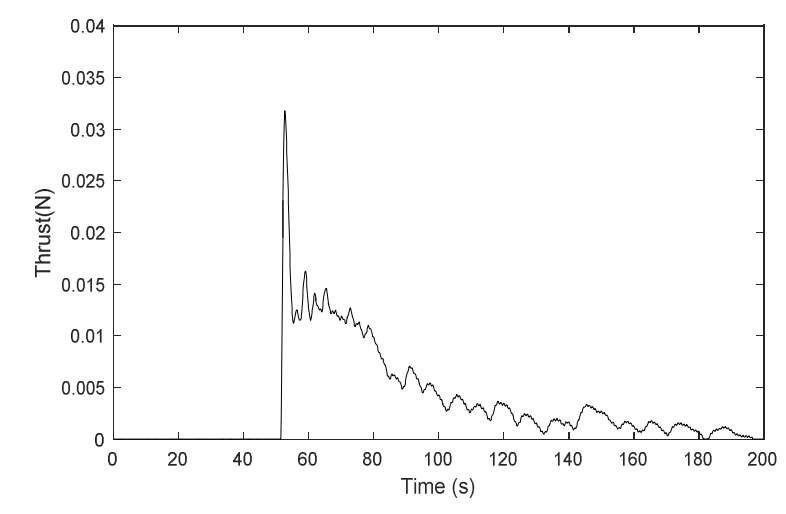

Fig. 5 Thrust performance for one-shot cycle

\footnotetext{
${ }^{3}$ Range of temperature from $298 \mathrm{~K}$ to $933 \mathrm{~K}$

${ }^{4}$ Range of temperature from $298 \mathrm{~K}$ to $500 \mathrm{~K}$

${ }^{5}$ No values at the operating temperature
} 


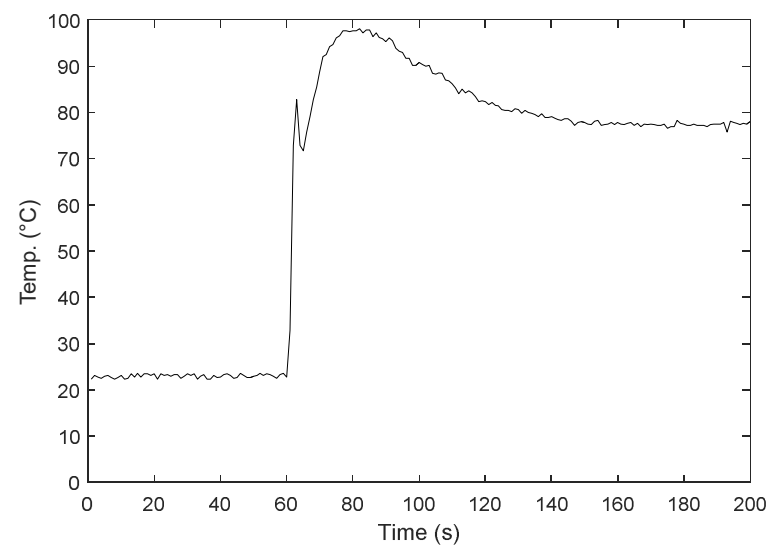

Fig. 6 Temperature response in the reaction chamber

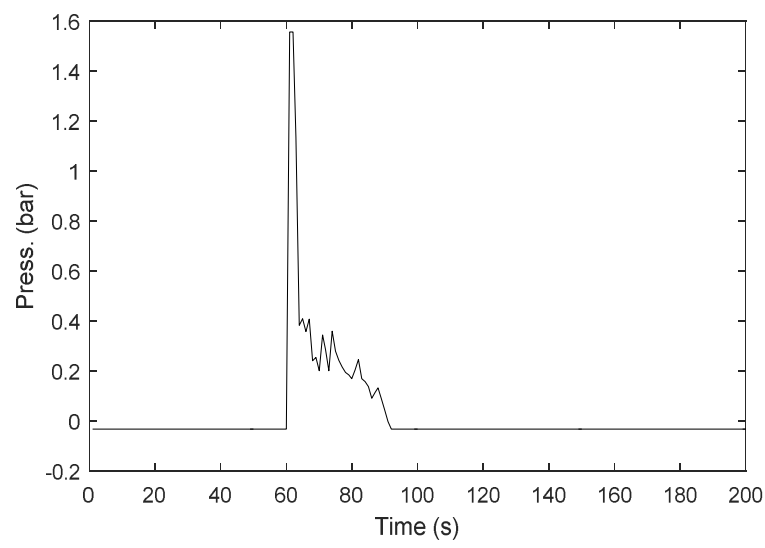

Fig. 7 Pressure response in the reaction chamber

The remaining propellant mass in the table represents the mass of unused aluminium wool, mass of sodium hydroxide and the mass of aluminium hydroxide measured after the experiment. That is the mass balancing equation in the reaction chamber is,

$$
(\mathrm{Al}+\mathrm{NaOH})_{\text {unused }}+\mathrm{Al}(\mathrm{OH})_{3}=7.46 \mathrm{~g}
$$

The initial mass of aluminium is $6 \mathrm{~g}$ and the mass of sodium hydroxide is $1 \mathrm{~g}$. Since these masses remained in the reaction chamber the mass of the hydroxyl ions is $0.46 \mathrm{~g}\left((\mathrm{OH})_{3}=0.46 \mathrm{~g}\right)$. Therefore, a molar balance of the governing chemical equation indicates that the mass of hydrogen produced is $0.0272 \mathrm{~g}$, which represents about $2 \%$ of the exhaust. Also, the amount of water that reacts with the aluminum is $0.487 \mathrm{~g}$ out of the injected $2 \mathrm{~g}$. The remaining $1.513 \mathrm{~g}$ of water (which is about $98 \%$ of the exhaust) changed from liquid to vapour phase during the reaction. 
Hence, using Equations Error! Reference source not found., Error! Reference source not found. and Error! Reference source not found., the enthalpy of formation is $-418.6 \mathrm{~kJ} / \mathrm{mol}$ and the temperature-dependent term is $3.5471 \mathrm{~kJ} / \mathrm{mol}$, giving the enthalpy of the chemical reaction, $h_{\text {chem }}$, as $-415.0529 \mathrm{~kJ}$ per mole of Al or $-3.7419 \mathrm{~kJ}$ (since only 0.009054 moles of $A l$ was consumed in the reaction). The input enthalpy of the oxidiser into the reaction chamber, $h_{i}$, is $-0.1930 \mathrm{~kJ}$ from $2 \mathrm{~g}$ of input. Therefore, the total enthalpy in the reaction chamber is $-3.9349 \mathrm{~kJ}$. A large portion of this energy is accounted for through the phase change of the incoming liquid water into vapour phase. The time history of the reaction chamber temperature and pressure can be used to track the liquid to gas transition as the reaction progresses, as illustrated in Fig. 8.

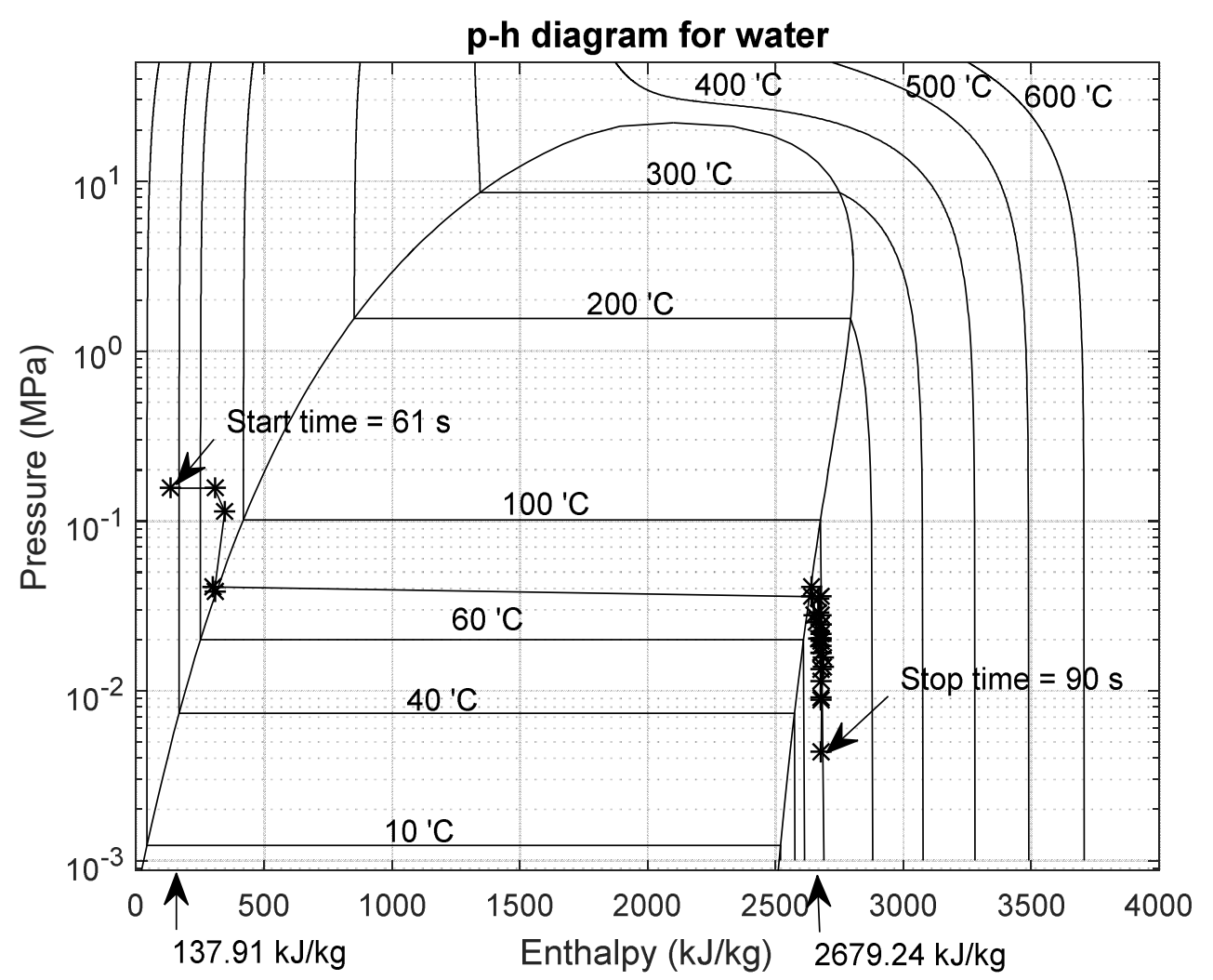

Fig. 8 P-h diagram of water showing the temperature-pressure relation in the reaction chamber

The specific enthalpy required for the phase change is found to be $2525 \mathrm{~kJ} / \mathrm{kg}$ (subtracting the start point from the stop point). But the mass of water vapour from the exhaust is $1.51275 \mathrm{~g}$, which represent about $98 \%$ of the exhaust. Therefore the energy used for the water phase conversion is $3.84 \mathrm{~kJ}$. The resultant energy difference is responsible for the increase in the kinetic energy, $K E$, of the reaction exhaust that resulted in thrust generation. The kinetic energy can also be expressed as a function of the exhaust mass flow rate by: 


$$
\begin{aligned}
K E & =\frac{1}{2} m v^{2} \\
& =\int \frac{1}{2} \dot{m} v^{2} d t
\end{aligned}
$$

If we assume a constant exhaust velocity, it implies the total impulse can be expressed as

$$
\begin{gathered}
I=\int \dot{m} v d t \\
I=m v
\end{gathered}
$$

Equation 11 can therefore be rewritten as

$$
K E=\frac{1}{2} \frac{I^{2}}{m}
$$

Substituting values from Table 4, the kinetic energy is therefore $\mathbf{0 . 1 4 9 8} \mathbf{k J}$, and represents about $\mathbf{4} \%$ of the overall energy generated by the reaction. The difference in the input and output enthalpies represents about $1 \%$ of the injected water that did not get into the reaction chamber but stick to the wall of the conducting pipe.

\section{IV.Conclusion}

The reaction between aluminium, water, and sodium hydroxide was used as the basis of a laboratory scale propulsion system in order to investigate the feasibility of this concept as a propulsion technology for future CubeSat applications. For the conditions investigated in this experiment and based on the simplified chemical reaction, the composition of the exhaust products was calculated to be $98 \%$ water vapour and $2 \%$ hydrogen gas. Approximately $96 \%$ of the total chemical enthalpy of reaction was consumed through the phase change of the liquid propellant into vapour phase within the reaction chamber. The remaining $4 \%$ was responsible for the thrust generation, which reached a peak value of $32 \mathrm{mN}$ for the proof experiment conducted within this study. The specific impulse was found to be approximately $45 s$ under these conditions, leading to a predicted $\Delta \mathrm{V}$ of about $80 \mathrm{~m} / \mathrm{s}$ for a $1.33 \mathrm{~kg}$ CubeSat with a propellant mass fraction of $17 \%$. Although the specific impulse is modest compared to conventional propellants, the low cost, low complexity, high density, and easy handling requirements for this propellant combination may make it a useful alternative for future CubeSat propulsion applications. Series of experiments were conducted to characterize the thruster. The uncertainty in the repeated thrust measurements is obtained as $\pm 0.03 N$, while that of temperature readings is calculated as $\pm 0.02^{\circ} \mathrm{C}$. The uncertainty in the repeated pressure reading is obtained as $\pm 0.6 \mathrm{bar}$. The 
uncertainty in the pressure readings is more, primarily due to different background pressure of the vacuum chamber during different experiments.

\section{Acknowledgments}

The first author would like to thank the management of Petroleum Technology Development Fund (PTDF) Nigeria for sponsoring the research work.

\section{References}

[1] Mueller, J., "Thruster Options for Microspacecraft: A Review and Evaluation of Existing Hardware and Emerging Technologies,” AIAA paper, 97-3058, Jul. 1997, pp.1-29. doi: 10.2514/6.1997-3058

[2] Janson, S. W., Helvajian, H., Hansen, W. W. and Lodmell, J., "Microthrusters for Nanosatellites," Proceeding of the Second International Conference on Integrated Micro Nanotechnology for Space Applications (MNT99), $\begin{array}{lllll}\text { Pasadena, } & \text { CA, } & \text { April } & \text { 1999, } & \text { URL: }\end{array}$ http://www.las.inpe.br/ jrsenna/AerospaceMEMS/Propulsao/mnt99.pdf [retrieved 12 February 2014].

[3] Helvajian, H. and Janson, S. W., "Small Satellites: Past, Present, and Future," AIAA Aerospace Press, Reston, VA, Aug. 2009. doi: 10.2514/4.989223

[4] Mukerjee, E. V., Wallace, A. P., Yan, K. Y., Howard, D. W., Smith, R. L. and Collins, S. D., "Vaporizing Liquid Microthruster," Sensors and Actuators A: Physical, Vol. 83, No. 1-3, May 2000, pp.231-236. doi: 10.1016/S0924-4247(99)00389-1

[5] Wright, W. P. and Ferrer, P., "Electric Micropropulsion Systems," Journal of Progress in Aerospace Sciences, Vol. 74, Apr. 2015, pp.48-61. doi: 10.1016/j.paerosci.2014.10.003

[6] Lewis, D. H., Janson, S. W., Cohen, R. B. and Antonsson, E. K., "Digital Micropropulsion," Sensors and Actuators A: Physical, Vol. 80, No. 2, Mar. 2000, pp.143-154. doi: 10.1016/S0924-4247(99)00260-5

[7] Ahmed, O. D., "Perforfance Characterisation of a Hybrid Propulsion System for Cubesat Missions," Proceeding of 51st AIAA/SAE/ASEE Joint Propulsion Conference, Orlando, 23 Jul. 2015, pp. 4033. doi: 10.2514/6.20154033

[8] CGG Technologies, “The Cool Gas Generator” URL: http://cgg-technologies.com/cool-gas-generator [retrieved 30 August 2016] 
[9] Cengel Y. A., Turner, R. H., and Smith, R., "Fundamentals of Thermal-Fluid Sciences," Applied Mechanics Reviews, Vol. 54, No. 6, 2001, pp. B110. doi: 10.1115/1.1421126

[10] Ma, G.-L., Dai, H.-B, Zhuang, D.-W., H.-J., and Wang, P., “Controlled hydrogen generation by reaction of aluminium/sodium hydroxide/sodium stannate solid mixture with water," International Journal of Hydrogen Energy, Vol. 37, No. 7, April 2012, pp. 5811-5816. doi: 10.1016/j.ijhydene.2011.12.157

[11] Larson, W. J., Henry, G. N. and Humble, R. W., Space Propulsion Analysis and Design, 1st ed., McGraw-Hill, New York, 1995, pp. 168-169

[12] Smith, E. B., Basic Chemical Thermodynamics, 5th ed., Imperial College Press, London, Apr. 2004, pp. 63. doi: $10.1142 / \mathrm{p} 324$

[13] Haynes, W. M., CRC Handbook of Chemistry and Physics, 95th ed., CRC press NW, USA, 2014, pp. 5-4, 5-13

[14] Abu-Eishah, S. I., Haddad, Y., Solieman, A. and Bajbouj, A., "A New Correlation for the Specific Heat of Metals, Metal Oxides and Metal Fluorides as a Function of Temperature," Latin American Applied Research, Vol. $34, \quad$ No. $4, \quad$ 2004, $257-265$, $\quad$ URL: https://www.researchgate.net/publication/221969233_A_new_correlation_for_the_specific_heat_of_metals_m etal_oxides_and_metal_fluorides_as_a_function_of_temperature [retrieved 12 February 2015].

[15] Knoll, A. K., Lamprou, D., Lappas, V., Pollard, M. and Bianco, P. “Thrust Balance Characterization of a $200 \mathrm{~W}$ Quad Confinement Thruster for High Thrust Regimes” IEEE Transactions on Plasma Science, Vol. 43, No. 1, Jan. 2015. pp. 185-189. doi: 10.1109/TPS.2014.2323417 